\title{
ACMD
}

Advisory Council on the Misuse of Drugs

Chair: Professor Les Iversen

Secretary: Zahi Sulaiman

$1^{\text {st }}$ Floor (NE), Peel Building

2 Marsham Street

London

SW1P 4DF

Tel: 02070351121

ACMD@homeoffice.gsi.gov.uk

Lynne Featherstone MP, Minister for Crime Prevention

Home Office

2 Marsham Street

London

SW1P 4DF

25 February 2015

Dear Minister,

\section{RE: Prevention of drug and alcohol dependence}

I am pleased to enclose the Advisory Council of the Misuse of Drugs (ACMD) Recovery Committee's briefing paper on the prevention of drug and alcohol dependence, which has been published today. This paper is also available with a non-technical summary version on the ACMD website. This briefing paper is aimed to support policy makers, commissioners and practitioners working in prevention as well as informing future recommendations by the ACMD.

In this paper, we describe the overall aims of substance use prevention and introduce a standard wording to describe the work carried out in this area. An increasing body of scientific research supports including drug prevention activities as part of wider strategies to promote healthy development and well-being. The paper recommends that those working in the prevention field should be encouraged to use a common language to help make prevention strategies more coherent.

The paper also details how prevention activities impact on outcomes for substance users. The ACMD recommends that authorities commissioning prevention programmes should bear in mind that drug and substance use prevention should be part of a more general strategy supporting all aspects of users' lives. 
The ACMD regards evaluation an important part of any prevention project as international evidence suggests many popular types of prevention activity are ineffective at changing behaviour, and a small number may even increase the risks for drug use. Research funders and charities should support high-quality evaluation research, especially economic evaluation.

We further recommend that policy-makers should be aware that it is possible to reduce adverse long-term health and social outcomes through prevention interventions, even for individuals who are not persuaded to abstain entirely from the use of drugs.

We welcome an opportunity to discuss the paper with you in due course.

Yours sincerely,

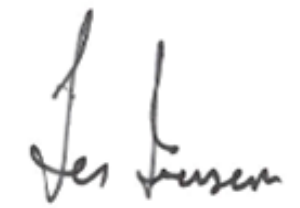

Professor Les Iversen

(ACMD Chair)

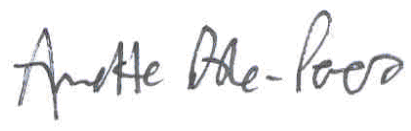

Annette Dale-Perera

(Co-Chair of the ACMD's Recovery Committee)

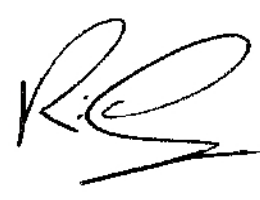

Richard Phillips

(Co-Chair of the ACMD's Recovery Committee)

CC: Rt Hon Theresa May MP, Home Secretary

Rt Hon Jeremy Hunt MP, Secretary of State for Health Jane Ellison MP, Parliamentary Under Secretary of State for Public Health 


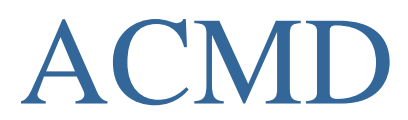

Advisory Council on the Misuse of Drugs

\section{Prevention of drug and alcohol dependence}

Briefing by the Recovery Committee

February 2015 


\section{CONTENTS}

Summary

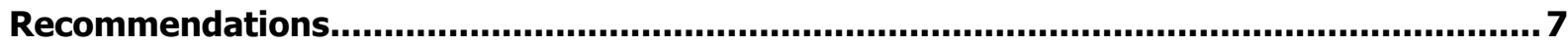

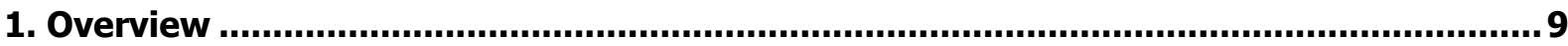

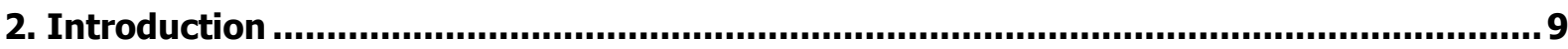

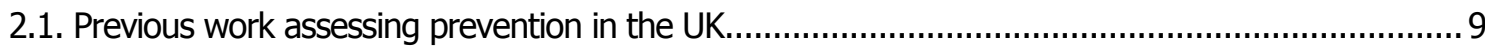

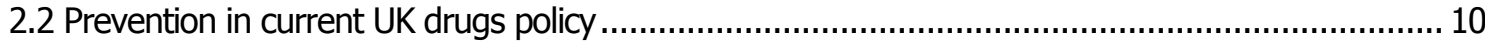

2.3 Understanding prevention 'systems' - how activities in one part of the system affect outcomes in

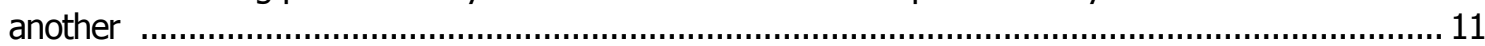

3. Defining drug prevention ....................................................................................... 12

4. How has our understanding of prevention been constructed? .................................... 15

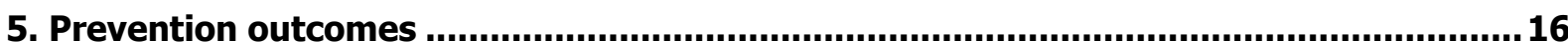

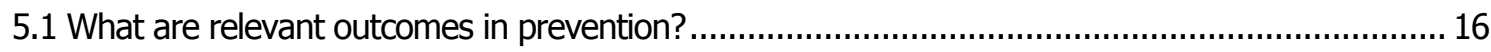

5.2. Prevention science: what 'works' in prevention? ............................................................. 17

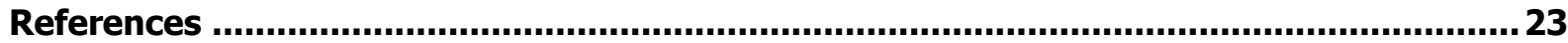




\section{SUMMARY}

- The briefing paper provides a summary of some of the key recent discussions in the substance use prevention field in order to support policy development, future Advisory Council on the Misuse of Drugs (ACMD) recommendations, and prevention providers in the UK.

- It is often difficult to identify directly labelled prevention activities in national policy and local delivery plans. Although this poses challenges for prevention scientists, practitioners and advocates, scientific research supports embedding universal drug prevention actions in wider strategies that aim to support healthy developmental and wellbeing in general. Targeted, drug-specific prevention interventions remain a valid approach to those individuals considered to be at a high risk of harm, although these groups also benefit from universal approaches.

- There is little clear evidence of 'what works' in drug prevention. However, recent advances in prevention science, based on life-course development research, community epidemiology, and preventive intervention trials, means that high quality evidence is being generated.

- There are a number of promising approaches that are likely to be beneficial if correctly implemented. These include pre-school family programmes; multi-sectoral programmes with multiple components (including the school and community) and some skills-development-based school programmes. However, there are a number of challenges in implementing these well organised programmes in routine practice, with fidelity, and on a large scale. These difficulties are more pronounced as robust national and local prevention systems are not well established.

- Environmental prevention activities such as pricing, taxation and marketing controls have shown evidence for success in reducing use and harms associated with alcohol and tobacco use. Although theory suggests that it may also be effective in responding to illegal drugs, opportunities for delivery of environmental prevention activities are restricted by the illegal nature of drugs.

- Understanding whether prevention represents good value for money compared to other activities or even compared to doing nothing at all is important, and so there is a need for economic analysis from UK implementations of prevention programmes. As the benefits of prevention are often long term, and are sometimes difficult to relate to policy priorities, additional considerations may be seen as more important than questions of (cost) effectiveness. These include politics, public demand for action, and media pressure.

- In contrast, there is strong evidence of prevention approaches that have consistently been shown to be ineffective at improving drug use outcomes. These include information provision (standalone schoolbased curricula designed only to increase knowledge about illegal drugs), fear arousal approaches (including 'scared straight' approaches), and stand-alone mass media campaigns. 


\section{RECOMMENDATIONS}

\section{The loM Prevention taxonomy should be accepted as a first step towards a common prevention language}

The use of a common prevention language and taxonomy is to be encouraged across the field in order to improve the coherence of prevention strategies. The US Institute of Medicine (IoM) prevention taxonomy (1994) provides one useful model in this regard, although further discussion should be loM held across sectors to ensure the appropriateness of this language.

\section{Commissioners of prevention activities should be mindful that drug and substance use prevention is likely to have only limited effects as a standalone activity. Prevention activities should be embedded in general strategies that support development across multiple life domains.}

A sophisticated, evidence-based view of prevention should be reflected in national policy and the recommendations of prominent groups such as the ACMD.

The challenges and complexities of prevention need to be more widely recognised across the range of stakeholders who have responsibility for prevention, particularly at a local level. Although some small benefits of prevention may be seen shortly after intervention, the majority will not manifest for several years. This means that prevention actions may be susceptible to short-term financial, political, and public-opinion pressures, and these may be reflected in commissioning plans. An evidence-based approach to prevention is one that considers long-term outcomes, the relationship between multiple risk behaviours, and natural trajectories of substance use. Ethics should be at the heart of all prevention activities.

Commissioners and prevention providers should be aware that although not understood well, actions in one part of the overall prevention 'system' may have beneficial or untoward effects in another. To understand the likely effects of a prevention initiative, the action must be located in an overall framework which includes (but is not limited to) such factors as the influence of national policy (which may be positive or negative in effect), national and local delivery systems, professional competencies, available resources and services, competing and compatible actions, and public acceptability of the action.

\section{Prevention projects should incorporate evaluation, and be developed from the findings of evaluation (ideally with economic evaluation)}

The UK prevention evidence base remains poor. Research funders and charities should support high-quality evaluation research, particularly those projects that include economic evaluation, address multiple behaviours, or consider at-risk individuals and populations.

\footnotetext{
Although knowledge about 'what works' in prevention is increasing, there are still uncertainties. Much more is known about approaches that do not seem to be effective. These include information provision (including knowledge-based school curricula), fear arousal approaches (including 'scared straight' approaches), and standalone mass media campaigns. It is recommended that local commissioners carefully consider their investment in such approaches. Organisations such as National Institute of Clinical Excellence (NICE) and Public Health England (PHE) will play important roles in navigating the evidence. PHE is about to publish a document mapping the international evidence onto UK interventions.

Commissioners of prevention are advised that for new prevention approaches, or actions without clear evidence of effectiveness, caution is warranted because some may be associated with unanticipated harmful outcomes. It is recommended that such actions should only be delivered as part of a research programme, where there is welldeveloped programme logic, and where costs and harms associated with a lack of action are considered to be high. The use of quality standards and guidelines on intervention development and delivery are recommended to guide such actions.
} 
Policy stakeholders should be mindful that prevention of adverse long-term health and social outcomes may be achieved even without drug abstention, although for some target groups drug abstention may be preferable.

Prevention actions should be justified on the basis of reducing long-term and meaningful adverse (individual and population) health and social outcomes. In this regard, it is important to be realistic about what prevention can achieve, and recognise that abstinence from drug use may not always be necessary to achieve these outcomes. 


\section{OVERVIEW}

The aim of this briefing paper is to provide a summary of some of the key recent developments in the substance use prevention field in order to support future ACMD recommendations and discussions. The paper builds on previous work by ACMD and others in this area and provides a description of the overall aims of substance use prevention and classifies activities through the use of a standardised taxonomy. The paper also considers the likely impact of prevention activities on substance use outcomes and how these relate to practical policy and practice objectives.

The view of prevention that is presented in this paper is one that is part of a 'complex system' of policies, interventions and activities and suggests that the greatest preventative benefits may be obtained through policies and actions that target multiple risk behaviours, of which substance use is just one. The paper does not make specific recommendations about what activities should be delivered, but presents evidence on the effectiveness of many popular approaches, and highlights popular strategies such as information dissemination and mass media responses to illegal drug use, which when delivered as stand-alone activities, are unlikely to have an effect on substance use.

Although this paper reflects wider discussions that view young people as the primary targets of prevention, it is acknowledged that older people are also valid and deserving recipients of preventative activity.

\section{INTRODUCTION}

\subsection{Previous work assessing prevention in the UK}

This section considers previous work by the ACMD and other groups in assessing the value and utility of prevention in the UK.

The ACMD substantially addressed preventative issues in its 2006 report Pathways to Problems. ${ }^{1}$ This report included, among others, nine wide-ranging recommendations in the prevention domain; from the provision of accurate and credible information about drugs, to the development of integrative policies with the ambition of lifting children out of poverty. The recommendations were underpinned by recognition of the importance of embedding research and evaluation in all prevention initiatives.

A follow-up report on the implementation of the Pathways to Problems recommendations was published in 2010. ${ }^{2}$ This described the Government's response to the recommendations and the ACMD's own assessment of progress. In general, the ACMD welcomed the progress that had been made with regards to prevention policy and initiatives, but recommended further mass-media-based prevention work in order to "inform young people of the real hazards of using tobacco, alcohol and other drugs" (recommendation 6.25).

Since the 2010 report the ACMD have not issued any substantive prevention-related advice. Each substancespecific report published by the ACMD has included general references to prevention and drug education, most commonly information provision (FRANK/DAN/Know the Score), and other resources such as Department for Education funded Mentor ADEPIS (http://mentor-adepis.org/). This is unsurprising as, with the exception of cannabis prevention, there have been few high quality evaluations of substance-specific prevention interventions.

NICE issued guidance on drug prevention for vulnerable young people in $2007 .^{3}$ This guidance focused on the importance of identifying young people vulnerable to using substances and recommended motivational interviewing, family-based interventions, and group-based behavioural therapy as evidence-based responses. However, the guidance was based on a small body of relevant evidence and so was limited in scope.

Furthermore, unlike NICE recommendations on medicines and health treatments, the NHS, and wider private and public sector are only advised to take public health guidance into account when developing prevention services, and there is no data to indicate how practice changed as a result of the 2007 work. It was announced by NICE in April 2014 that these guidelines were to be updated, reflecting developments in the evidence base. 
In its final report, the UK Drug Policy Commission (UKDPC) (2012) evaluated drug prevention in a similar manner to the ACMD in 2006. It recommended policy actions that responded to structural problems that increased the likelihood of drug use, the development of early interventions and family support, and the provision of evidence-based programmes. Regarding prevention activities, the UKDPC advised against 'drugspecific education', and highlighted the importance of supporting schools to implement broader programmes that aimed to build self-efficacy, help with impulse control and teach life skills, preferably as part of the national curriculum.

\subsection{Prevention in current UK drugs policy}

The 2010 Drugs Strategy ${ }^{4}$, Reducing demand, restricting supply, building recovery: supporting people to live a drug-free life, included a number of prevention-related priorities. The strategy proposes a 'whole life approach to drug use' through breaking inter-generational paths to dependency; providing good quality education and advice so that young people and their parents are provided with credible information to actively resist substance misuse; use the creation of PHE to encourage individuals to take responsibility for their own health; and to intervene early with young people and young adults.

While the main focus of the strategy is on recovery, it recognises that the majority of young people do not use drugs and most of those that do, are not dependent. While the 2010 strategy did not outline in detail actions regarding non-dependent drug use in young people, subsequent annual reviews (2012 and 2013) identified the following major prevention initiatives (those still being implemented at the time of writing):

- $\quad$ Revised advice from the Association of Chief Police Officers for managing drugs and drug related incidents in schools;

- Introduction of the Troubled Families programme, with funding committed until 2016;

- Introduction of the Family Nurse Partnership programme; and

- Establishment of the Early Intervention Foundation, Centre for Analysis of Youth Transitions, and Alcohol and Drug Education and Prevention Information Service (ADEPIS) to support the implementation of evidence based prevention practice.

The Drug Strategy 2010 Evaluation Framework (2010) ${ }^{5}$ presents a framework for evaluating the effectiveness and value for money of the strategy. Two relevant prevention activities are identified and these are described below; 'Early Intervention' and 'Education and Information approaches'. The frameworks are complex, but also realistic, and there is an acknowledgement that it is difficult to conduct an evaluation of national policy where it is not possible to conduct a traditional randomised controlled trial (RCT), and that many policy actions are 'hidden' in other activities (e.g. reduction in relative poverty as a preventative action).

The Early Intervention stream describes activities that are designed to alter early environments and prevent future adverse outcomes, including drug use. The Government's estimated expenditure in 2011/12 for this stream was $\mathrm{f} 341 \mathrm{~m}$, and included funding of named programmes such as the Family Nurse Partnership, Sure Start, and the Intensive Family Pathfinders/Family Interventions Programme, none of which directly targets drug use. It is worth noting, however, that of these three named initiatives, only the Family Nurse Partnership appears to be currently fully supported, with many Sure Start centres having recently closed, and the Family Interventions Programme is not currently active. This integrated policy approach recognises wider societal and structural determinants of health behaviour, and acknowledges that responsibility for prevention policy lies across government departments. This also presents challenges though, when trying to identify prevention activities and expenditure in policy, or perhaps more importantly, to evaluate its effectiveness.

The Education and Information stream of the framework is an explicit preventative action, meaning evaluation and costing is relatively easy. The evaluation logic model assumes a 'rational consumer' or 'information deficit' approach to drug use in young people, which are not generally supported by the evidence. ${ }^{6}$ The evaluation logic model also proposes that information-based approaches such as FRANK alter the "drug using 
environment" thus reinforcing abstention or making users more likely to reduce or quit. At best, information provision improves drug-related knowledge, but there is no evidence that information provision alone reduces drug use (see Section 5.2 below). Information-based approaches are different from social norms approaches which aim to correct misperceptions about the frequency, uniqueness, and acceptability of a behaviour (e.g. Moreira et $a l ., 2009^{7}$ ), and thus might be considered to alter the social environment of use. Finally, although social marketing approaches to intervention are included in this stream, they have generally been delivered in UK drug prevention actions as a population segmentation and implementation technique, not an active intervention in itself. ${ }^{8}$

\subsection{Understanding prevention 'systems' - how activities in one part of the system affect outcomes in another}

Successful drug prevention is not just about what activities or programmes are delivered, but also how prevention systems are organised and implemented. The World Health Organization Substance Abuse Instrument for the Mapping of Services ${ }^{9}$ presents one illustrative model for understanding the structure and function of national prevention systems and how these interact with macro- and micro-level factors to influence population health. Such models are useful to help understand how prevention interventions and programmes may be affected by structural and systemic factors. In the WHO model for example, macro-level factors such as drug policy determines the availability of structural resources and direction of preventative action. Within this policy environment, system resources and qualities contribute to prevention effectiveness. Indicators of population health (e.g. prevalence of drug use, drug-related mortality and morbidity) are subsequently used to evaluate the impact of prevention actions. The view of prevention presented in this paper is one of generic developmental activities, supplemented by specialised substance use prevention (see section 3 below). Therefore, a more complex model would have to be prepared to describe UK 'prevention systems', which would include policy and strategies from a wide range of fields.

In order to understand the potential impact of suites of prevention actions, it is also important to also consider 'Infrastructure Interventions' ${ }^{10}$, i.e. interventions that develop prevention policy, structure, organisation, workforce, ethos and professional culture. To date, there has been little research in this area and it is therefore uncertain what actions are necessary to optimise prevention systems.

In parallel with developments in other areas of health and social welfare policy, it is useful to incorporate a 'complex systems' approach to prevention. A complex system is one that is "adaptive to changes in its local environment, is composed of other complex systems (for example, the human body), and behaves in a nonlinear fashion (change in outcome is not proportional to change in input)" ${ }^{11}$ Complex systems have properties that are a feature of the system as a whole, therefore while individual activities may not produce directly identifiable benefits for health, there may be knock-on effects and interactions with other activities until a tipping point is reached. Examples of complex systems include primary care, communities, and schools. Interventions delivered in these settings may themselves be simple or complicated, but the complex systems approach suggests that interaction occurs between components of an intervention as well as between the intervention and the context in which it is implemented.

One example of a complex system approach to prevention is given by Sussman and colleagues. ${ }^{12}$ Using the example of community-based tobacco use prevention, they note that community-wide activities, including multiple modalities (e.g. school + mass media), have generally not been found to be more effective than single modality actions. They argue that studying tobacco use prevention as a complex system may allow for a careful selection of programme type combinations, and thus have greater impact on behaviour. As a simple example, a mass media campaign may increase the number of current smokers interested in quitting, or it may increase the target population for a second intervention designed to provide pharmacotherapy to support smoking cessation. However, if there is a lack of community provision of cessation services, then subsequent mass media interventions may be less likely to motivate smokers to quit. Similarly, if both mass media campaigns and school-based programmes reduce the number of young people likely to initiate smoking, each 
will reduce the number in the target population for the other. Finally, if mass media campaigns lead to an increase in presentations at community cessation services, then disinvestment of mass media will result in a decrease in service presentation. Interventions delivered in complex systems may also have benefits for those who are not directly targets, and thus benefit population health. In this example, non-smokers also benefit from preventative activities because of reduced exposure to second-hand smoke, and society benefits because of a net reduction in costs resulting from premature morbidity/mortality (e.g. reduction in smoking-related healthcare costs, reduction in salary-related tax contributions, costs to business, which exceed revenue generated from tobacco sales ${ }^{13}$ ).

There has been less consideration of complex systems with regards to illegal drug prevention, although there is emerging evidence with regards to the interdependence of activities. For example, the US National Youth Anti-Drug Media Campaign ${ }^{14}$ was a well-funded (US \$1 billion) comprehensive social marketing strategy that aimed anti-drug messages at young people aged between 9 to 18 years of age. The campaign ran between 1999 and 2004 and high-quality evaluation suggested that it was ineffective, and may even have had unfavourable effects in some young people exposed to it. ${ }^{15}$ However, when evaluated in young people who had simultaneously received an evidence-based classroom-based curriculum (Project ALERT), positive synergistic effects on cannabis use were found. ${ }^{16}$

In such models, national substance use policies are hypothesised to be important influences on prevention effect. It has been suggested that one of the reasons why the majority of alcohol prevention initiatives have historically had little or no effect is because 'boundary conditions' have not been set by government ${ }^{17}$. It has been argued that in the absence of strong government control of the alcohol market (e.g. through pricing legislation and restriction of marketing) important social and policy conditions have not been met which would beneficially moderate programme effects. This contrasts with tobacco control, with draft regulation tabled on standardised packaging, and strong local advocacy as part of 'truth' movements targeting the tobacco industry $^{18}$. Similarly, while there is little evidence to suggest that legal classification of drugs directly influences use, national laws may positively or negatively influence prevention efforts through mechanisms such as influencing social norms towards drugs or reinforcing stigmatisation and exclusion of users.

\section{DEFINING DRUG PREVENTION}

There is no commonly accepted definition of 'drug prevention' or precisely what type of activities it describes. At a simple level, drug prevention may include any policy, programme, or activity that is (at least partially) directly or indirectly aimed at preventing, delaying or reducing drug use, and/or its negative consequences such as health and social harm, or the development of problematic drug use. ${ }^{19}$ There are commonalities between preventative responses to illegal drugs, alcohol, and tobacco and so these substances should also be considered part of this definition. This definition of drug prevention may also include some types of harmreduction activities, although this is not generally accepted.

Drug prevention is differentiated from drug education as the latter aims to provide information and advice about drugs upon which individuals can base decisions. Unlike prevention, it is not the primary objective of drug education to change behaviour, although prevention activities may include prominent educational components.

Drug prevention activities are commonly thought of as being most relevant to young people, and most research and activity is concentrated on this age group. However, prevention is relevant across the lifespan, for example, in reducing prescription drug misuse or alcohol use in older adults.

The US Institute of Medicine prevention classification system ${ }^{20}$, validated in 2009, provides a system for describing the form of prevention (figure 1). Applied to the drugs field it illustrates the continuum of services/interventions between prevention, treatment, recovery and harm reduction and is a useful tool for describing a conceptually unified and evidence-based continuum of services. This taxonomy also provides a common language to describe prevention and assist in the planning, delivery, and evaluation of activities. 


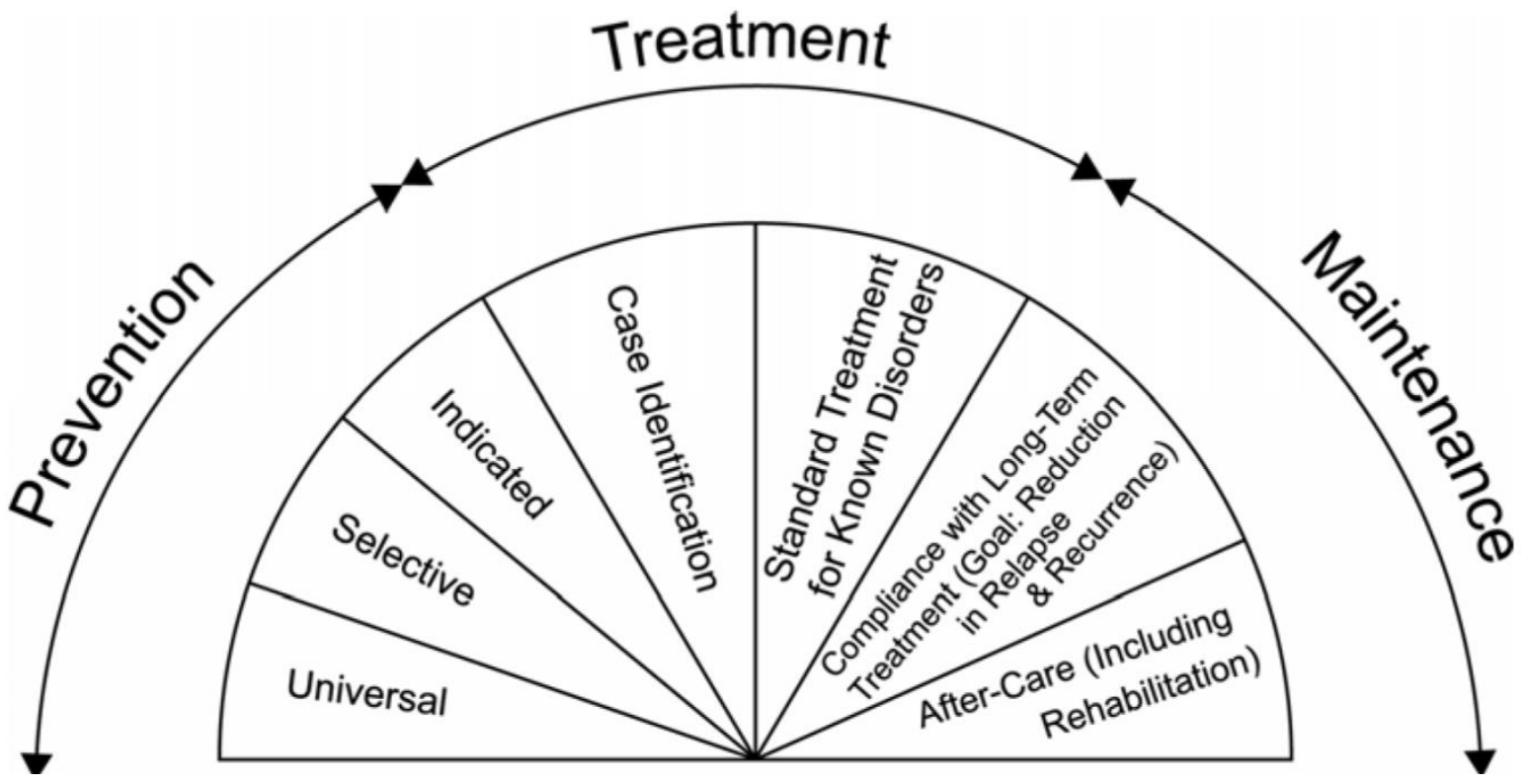

Figure 1 The Institute of Medicine model of prevention (1994; 2009)

Briefly, Universal approaches to drug prevention usually take a whole population approach and are delivered regardless of the level of risk or propensity to use drugs in the population. Examples include mass media campaigns and school curricula.

Selective prevention is delivered to individuals or groups (often, although not exclusively, vulnerable groups) whose risk of drug use or associated harms is considered significantly higher than average because the biopsychological, behavioural, or social risk factors they face are more pronounced than the general population. Selective prevention may also be delivered to groups or individuals who already use drugs in order to prevent harm, or in order to reduce the likelihood of progressing into more harmful patterns of use. Examples include family skills programmes for families affected by substance use, or brief interventions for club drug users in night-time leisure environments.

Indicated drug prevention exclusively targets individuals who are identified or screened as having an increased vulnerability to drug use or harmful patterns of use based on individual assessment (cf selective prevention). Examples include individual counselling for adolescents with impulse control difficulties, or referral to more intensive support for individuals who present to $A \& E$ as a result of drug use.

Health promotion activities are not included in the loM model, but are relevant in discussion of responses to substance use. Health promotion (sometimes known as Positive Development Strategies) are similar to universal approaches in that they target an entire population, but have the goal of enhancing strengths so as to reduce the risk of later problem outcomes and/or to increase prospects for positive development. Such approaches differ from universal prevention in that while prevention generally focuses on the amelioration of risk factors in order to prevent a specific outcome, health promotion focuses on those activities which support positive health and wellbeing as part of day-to-day life, and there is usually less emphasis on particular outcomes.

Although it falls outside of the loM framework, there is increasing interest in Environmental prevention. ${ }^{21}$ These are interventions that aim to limit the availability of drug use opportunities, through system-wide policies, restrictions and actions, and are designed to affect the immediate cultural, social, physical and economic environments in which people make their choices about drug use. It has been argued that because environmental interventions limit the opportunities for action, they are more likely to result in changes in behaviour. ${ }^{21}$ By definition, the control of drugs under the Misuse of Drugs Act 1971 is an environmental intervention, but examples of environmental prevention for illegal drug use are less common than responses 
to alcohol and tobacco, which include actions such as reducing alcohol outlet density, or pricing and taxation responses. 'Drug driving' laws may be considered an environmental intervention because although using illegal drugs is not an offence, driving while intoxicated is, and the laws are designed to restrict drug use opportunities. Similarly, some workplace drug policies have been shown to lead to a reduction in self-reported drug use. ${ }^{22}$ A comparison of research findings from the most effective environmental prevention approaches to alcohol and tobacco with the most effective types of other intervention approaches seems to support this position $^{21}$.

Foxcroft ${ }^{21}$ has proposed that the loM model be extended in order to better incorporate functional perspectives, so that interventions are also classed as Environmental, Developmental or Informational preventive measures. Environmental functions have been discussed above; Developmental approaches focus on the development of skills that are key in socialisation and social development of appropriate behaviours; Informational prevention approaches aim to increase knowledge and raise awareness about specific risk behaviours, generally through communications. In this expanded taxonomy, an example of a universalinformational approach would be drugs information provided by FRANK; while an example of a selectiveinformational approach would be dissemination of on-site drug testing data at a music festival.

Preventative responses to drug use have historically most commonly been delivered in isolation; the objective of such strategies is primarily designed to prevent or reduce drug use (including alcohol and tobacco).

However, research evidence reveals a complex array of determinants of initiation, maintenance or cessation of drug use (e.g. Hawkins et al. $1992^{23}$ ) and these are influenced by interlinked biopsychological, societal, structural and environmental factors (e.g. Birckmayer et al., $2004^{24}$ ). This has led to the identification of risk factors that predict an increased likelihood of behavioural expression or problems, and protective factors that mediate or moderate exposure to risk or directly decrease the likelihood of problems. Importantly, many of these factors are also important determinants of other risk behaviours, or healthy development in general. ${ }^{25} 26$ 27

There is also emerging evidence to suggest a common underlying aetiology for a variety of dysfunctional or risk behaviours in young people. ${ }^{28}$ This evidence suggests that drug use and problematic drug use are located on the same dimensional continuum as pre-drug-use behaviours, and rather than drug use being pathological in itself, it is an indicator of an underlying latent trait that includes dysregulation, disinhibition, behaviour undercontrol or externalising behaviour. In simple terms, this research suggests that drug use is just one manifestation of an underlying behavioural trait, and that differences in propensity to use drugs or engage in other risk behaviours is (partly) determined by differences in individual liability to the influence of various risk and protective factors.

In accordance with such models, epidemiological studies show that there is a clustering of risk behaviours in young people, and experiences of multiple risk are associated with effects beyond the cumulative effects of individual health risk behaviour, including poorer emotional wellbeing, psychological distress, and injury. ${ }^{29}$ There is emerging evidence to suggest that interventions for multiple health behaviours are (cost) effective (e.g. Hale and Viner, $2012^{29}$; Prochaska et al., $2008^{30}$; Werch et al., $2010^{31}$ ) suggesting that they may constitute a more efficient means of preventing risk behaviours in adolescence than single domain approaches (i.e. drugs only).

Although this model suggests that it would be useful to implement actions that target common determinants of all types of psychoactive substances, including alcohol and tobacco, each domain is governed by different policies and it is important to acknowledge that society views these behaviours differently. Therefore, although there may be shared biopsychological mediators of use, societal, structural and environmental factors may differ. For example, although alcohol use is normalised in society and the revenues generated from sales contribute directly to the national economy, this is not the case for illegal drugs and no types of use by young people are tolerated by general society (see Measham and Shiner, $2009^{32}$ for a discussion of 'normalisation'). In practical terms this may mean that while interventions that target biopsychological 
mediators of multiple risk behaviour may be useful (e.g. personality, cognition, socialisation, decision-making skills), many other types of complementary activities, particularly environmental interventions (e.g. regulation of legal supply, marketing), may not be appropriate.

As suggested above, prevention science has identified many different risk and protective factors for substance use (e.g. Hawkins et al., $1992^{23}$ ) and those at the individual, family, or community level are typically the targets of prevention interventions. However, there are also strong associations between substance use and a range of important societal, structural and environmental moderators including (but not limited to) connectedness to others, family structures, gender, community cohesion and wellbeing, inequality and exclusion, deprivation, cultural attitudes and beliefs, (formal and informal) marketing of addictive goods, attachment to social institutions, national norms and values, physical capital and economic forces. The majority of these are beyond the control of the individual, and are unlikely to be affected by typical prevention interventions. The influence that these have over the behaviour of individuals and populations, and the malleability to intervention/policy are also difficult to measure. Therefore, in considering the impact and effectiveness of prevention policy and interventions, the broader aspects of the system needs to be described.

\section{HOW HAS OUR UNDERSTANDING OF PREVENTION BEEN CONSTRUCTED?}

For illegal behaviours such as drug use, prevention is justified as a mechanism to reduce harm and to promote good health and social wellbeing. However, it should also be recognised that prevention actions that restrict behavioural opportunities may also be interpreted as ways of governing society and its problems (and by extension, 'problem people'). Specific kinds of knowledge may be sometimes used to construct and represent these problems, and used to justify responses that may not otherwise be acceptable for other types of behaviour. Sociologists often argue that the definition of a behaviour or an activity as a 'social problem' (such as drug use) is determined to a greater extent on the 'claims-making' activities of those who find the behaviour or activity unacceptable, rather than evidence that the behaviour actually leads to health and social harms. ${ }^{33}$ This has led some authors to suggest that the type of drug prevention activities delivered represent an ideological 'litmus test'. ${ }^{34}$

To varying degrees all health issues with a social dimension are socially constructed, but the content and character of these change over time (e.g. changing public attitudes to alcohol and drunkenness; tobacco and smoking in public places; legalisation of cannabis use in some states of the USA). The analyses presented in the critical prevention literature (e.g., Brown, $2001^{35}$; Gorman, $2005^{36}$; Gandhi et al., 2007 ${ }^{37}$; Midford, 2008 ${ }^{38}$ ), suggest that many responses to drug use are also socially constructed, with researchers and advocates of evidence-based prevention performing the role of 'claims makers' about what is a problem, and what the best response should be. Much of this discussion focuses on whether interventions are effective, and therefore whether it is the intention to change or restrict behaviour in the absence of clear health and social benefits for the recipient. It is also important to examine whether participation in some types of drug prevention intervention may lead to stigmatisation and an increase in inequalities; whether as a result of recipients being labelled as 'drug users', or because potentially effective prevention activities are withheld because of society's view of what an 'acceptable' response to drug use and drug users should be. ${ }^{39}$ For example, if the prevailing view is that society should be 'tough' on drugs and drug users, then prevention policy and intervention may respond accordingly (e.g. fear arousal, punitive, and 'scared straight' approaches), even if there is little evidence that such approaches are effective.

Regardless of the ethical or moral approach taken towards drugs and drug users, it has been argued that certain principles should underpin all prevention activities (summarised by Brotherhood and Sumnall, $2011^{19}$ ). Prevention should:

- respect participants' rights and autonomy

- $\quad$ provide real benefits for participants (i.e. ensuring that the programme is relevant and useful for participants) 
- cause no harm or substantial disadvantages for participants

- obtain participants' consent before participation

- ensure that participation is voluntary

- $\quad$ tailor the intervention to participants' needs

- involve participants as partners in the development, implementation, and evaluation of the programme.

\section{PREVENTION OUTCOMES}

\subsection{What are relevant outcomes in prevention?}

Typically, the goal of effective drug policy is to reduce adverse health or social outcomes associated with use, and to improve population wellbeing. ${ }^{40}$ However, most prevention interventions are justified on the basis of potential impact upon simple indicators of drug use such as age of initiation, cessation or de-escalation of use, problematic use or dependence. These are, of course, important objectives and are justified on the basis that drug use, or at least certain patterns of use, are directly or indirectly associated with a greater probability of adverse health or social outcomes. For example, earlier age of initiation of cannabis has been associated in a number of studies with a range of adverse outcomes, including greater likelihood of reporting dependence in adulthood; an increase in general risk propensity; poorer educational outcomes (thus potentially leading to reduced economic achievement in adulthood), impaired cognitive functioning, psychopathology, initiation of tobacco use, etc (e.g. Hall and Degenhardt, $2009^{41}$ ).

As it is difficult and expensive to assess such policy objectives in large numbers of participants taking part in research trials, most prevention research focuses on surrogate indicators, such as period prevalence of substance use (e.g. use in the previous month) or a diagnostic classification (e.g. 'harmful' patterns of use). However, the predictability of such surrogate measures has been called into question. ${ }^{42}$ Predictability is defined as the extent to which study outcome measures relate to meaningful health or social outcomes; for example, injury, morbidity, mortality, quality of life, educational and economic achievements. Subsequently, it is difficult to relate a surrogate indicator of substance use, such as use in the previous year or month to meaningful outcomes. It has been argued that many prevention interventions have been evaluated with regards to their success at changing surrogate outcomes rather than policy- and practice-relevant health and social outcomes. ${ }^{42}$ For example, a local commissioner of drug services may wish to know whether a targeted prevention initiative will contribute to a long-term reduction in problematic drug use presentations. As few prevention research interventions track participants for sufficient follow-up times, and because there is no clear relationship between surrogate outcomes and presentation at drug services, it is not currently possible to answer such questions.

Regardless, even where successful, intervention effect sizes are typically small (e.g. Faggiano et al., 20056). Where a study has a large sample size, even small effects may be statistically significant. For example, one evaluation of the Life Skills Training programme, a popular and well-researched school substance use prevention programme, showed that a control group scored on average 2.0 on a 9-point scale of drinking frequency, compared to an average score of 1.73 for the intervention group. Although statistically significant, and the project was deemed a success, the predictability and practical significance of such small outcomes for policy and practice is questionable if not delivered at a national level. ${ }^{43}$

As well as the evaluation of the overall outcomes of prevention initiatives (typically intervention versus controls), researchers also seek to understand the differential effects of programmes in population subgroups. Although some studies have reported that intervention effectiveness does not differ across subgroups (e.g. Botvin et al., $1998^{44}$; Spoth et al., 2006 ${ }^{45}$ ), others have reported differential outcomes when examining 'at-risk' participants (e.g. those displaying elevated levels of targeted risk factors or behavioural outcome) in more detail. ${ }^{464748}$ Some prevention programmes have been shown to be effective only in the highest-risk groups ${ }^{49}$ ${ }^{50}$, while others show stronger effects in lower-risk groups. ${ }^{51}{ }^{52}$ Understanding differential prevention impact is 
important because it not only allows for better targeting and refinement of approaches, but it may also reduce the likelihood of interventions reinforcing health and social inequalities.

Furthermore, evidence suggests that participants considered at greater risk can also equally benefit from universal prevention interventions, suggesting that specialist intervention is not always required. For example, Spoth and colleagues ${ }^{53}$ examined the outcomes of the lowa Strengthening Families Programme and the Preparing for the Drug Free Years intervention in the USA. Despite both approaches being designed for the general population, compared to a control condition of minimal contact, both interventions provided comparable benefits on alcohol and drug use initiation, regardless of family risk status.

\subsection{Prevention science: what 'works' in prevention?}

Prevention science has emerged as a discipline built on the integration of life-course development research, community epidemiology, and preventive intervention trials. ${ }^{54}$ Through evaluation, a number of programmes and policies have been identified as being effective in preventing the development of health and social problems,$^{55}$ and quality standards have been established which outline criteria for the internal consistency, efficacy, effectiveness and dissemination of prevention activities. ${ }^{56} 57$

In the UK (and internationally), while some drug prevention interventions have been evaluated, the majority in use have not. It should not be presumed that unevaluated actions will be equally or more effective than those that have undergone rigorous evaluation. ${ }^{55}$ Many widely used approaches have been evaluated and have been found to be ineffective, and some have even been shown to be iatrogenic (i.e. lead to an increase in drug use or other risk behaviour ${ }^{58}$ ). Not only do these activities often utilise public funds that might more productively be used to implement other programmes that have demonstrated effectiveness, but delivery of ineffective programmes might be considered unethical as they do not support healthy development or wellbeing. Where evidence of effectiveness is unclear, it is important that policies and interventions are implemented only as part of sufficiently funded scientific research projects to evaluate the effectiveness of these actions using robust research methodologies. Research identifying the active components of intervention is also essential in order to refine activities. Prevention research trials should, where possible, adopt a realist approach to identifying intervention effectiveness, seeking to understand mechanisms of change, differential outcomes for sub populations, and the effects of context and complex systems on outcomes. ${ }^{59}$

There are a large number of reviews which identify 'what works' in prevention and it is beyond the scope of this briefing paper to summarise them. The United Nations Office on Drugs and Crime (UNODC) have published useful guidelines that summarise the scientific evidence, and describe interventions and policies that have been found to result in positive prevention outcomes ${ }^{60}$. Databases such as the UK Department for Education funded Centre for Analysis of Youth Transitions (CAYT) repository of evidence-based services and programmes for young people ${ }^{61}$, the Alcohol and Drug Education and Prevention Information Service (ADEPIS) and the USA National Registry of Evidence-Based Programmes and Practices (NREPP ${ }^{62}$ ) provide information of the evidence of effectiveness on a number of named prevention programmes and activities. A forthcoming PHE publication will review prevention across the life course, rate the strength of the evidence and give examples of programmes already in use in England. The Cochrane Drugs and Alcohol review group ${ }^{63}$ have published several high-quality systematic reviews on specific substance use prevention approaches, and it is recommended that the interested reader consults these.

Understanding whether a prevention activity is 'effective' or not depends upon a number of qualifying criteria, ${ }^{19}$ including (but not limited to):

- How 'prevention' activities are labelled, defined, and classified (see section 3 above)

- What activities are classed as prevention - e.g. drug specific; general development and policy; programmed/manualised approaches; screening, brief individualised advice and referral etc

- Quality thresholds used in evidence reviews determining what makes a 'high - quality' research study, e.g. RCT vs other types of research design 
- The practical importance and predictability of the outcomes investigated, and the longevity and size of effect (see section 5.1 above)

- Independent replication by researchers other than those involved in the development of the activity

- Whether the findings of the intervention research can be generalised to (e.g. other types of population in the same or other countries).

One recent piece of research, commissioned as part of the EC-funded ALICE-RAP project, broadly summarised the evidence of effectiveness for a wide range of policies and interventions (including preventative activities) designed to address young people's 'addictive behaviours' ${ }^{64}$ High-quality systematic reviews of quantitative primary studies evaluating the effectiveness of policies or interventions (including Cochrane Reviews) were reviewed if they were written in English, provided outcomes for young people aged 25 years or under; reviewed a policy or intervention approach addressing substance use (alcohol, tobacco, illegal drugs) or gambling, or related health and social harms; and reported behavioural outcomes (cf. knowledge and attitudes). Results were organised according to a bespoke classification of activities:

- Control and regulation of supply

- Gambling/substance-free zones

- $\quad$ Age limits

- Taxation and pricing

- Control and regulation of advertising, marketing and sponsorship

- Warning labels

- Prevention programmes

- Treatment and social reintegration

- Harm reduction

- Delivery structures and quality assurance measures

Despite the extensive research undertaken in these areas, there was little high-quality evidence to conclude 'what works'. Results for clearly labelled drug prevention approaches (cf. manualised programmes) are presented in table 1 below. Overall, and based on approaches where good evidence was available, the authors concluded that:

- With regard to school-based prevention, information provision alone ('drug education') was not considered an effective strategy, whereas some types of skills development programmes were found to prevent alcohol, tobacco and some types of illegal drug use. However, as studies often examined complete manualised classroom - based programmes, it was not possible to identify effective mechanisms of change or mediating programme components.

- Stand-alone mass media campaigns for illegal drug use were at best ineffective, and at worst associated with increased drug use. Mass media campaigns should therefore only be delivered as part of multiple component programmes to support school-based prevention. 


\begin{tabular}{|c|c|}
\hline $\begin{array}{l}\text { Beneficial } \\
\text { Interventions and approaches that } \\
\text { showed robust evidence for positive } \\
\text { effects on addictive behaviours. } \\
\text { Research evidence for the intervention } \\
\text { or approach is likely to be transferable } \\
\text { to young people in other geographies. }\end{array}$ & - $\quad$ No evidence identified \\
\hline $\begin{array}{l}\text { Likely to be beneficial } \\
\text { Interventions and approaches for } \\
\text { which there was some, but limited, } \\
\text { evidence for positive effects on } \\
\text { addictive behaviours. Research } \\
\text { evidence for the intervention or } \\
\text { approach was likely to be transferable } \\
\text { to young people in other geographies } \\
\text { but caution is warranted and } \\
\text { adaptation studies are recommended. }\end{array}$ & $\begin{array}{l}\text { Universal programmes such as the Good Behavior Game; Life } \\
\text { Skills Training; and Unplugged in reducing alcohol misuse } \\
\text { Universal family-based programmes in producing } \\
\text { small/medium to long-term reductions in alcohol misuse } \\
\text { Web-based and individual face-to-face feedback in reducing } \\
\text { alcohol misuse up to three months after intervention } \\
\text { Brief motivational interviewing in producing short- and } \\
\text { medium-term reductions in tobacco use } \\
\text { Multisectoral (including the school) and community-based } \\
\text { interventions at preventing tobacco use, particularly when } \\
\text { delivered with high intensity and based on theory } \\
\text { Addition of media-based components (supporting the core } \\
\text { curriculum) to school-based education at preventing tobacco } \\
\text { use } \\
\text { Pre-school, family-based programmes in producing long-term } \\
\text { reductions in the prevalence of lifetime or current tobacco } \\
\text { use, and lifetime cannabis use } \\
\text { Multisectoral programmes with multiple components } \\
\text { (including the school and community) in reducing illegal drug } \\
\text { use } \\
\text { Motivational interviewing in producing short-term reductions } \\
\text { in multiple substance use } \\
\text { Some skills-development-based school programmes in } \\
\text { preventing early stage illegal drug use. }\end{array}$ \\
\hline $\begin{array}{l}\text { Mixed evidence } \\
\text { Interventions and approaches for } \\
\text { which there was some evidence of } \\
\text { positive effects in favour of the } \\
\text { intervention, but that also showed } \\
\text { some limitations or unintended effects } \\
\text { that would need to be assessed before } \\
\text { implementing them further. }\end{array}$ & $\begin{array}{l}\text { Whole school approaches that aim to change the school } \\
\text { environment on use of multiple substances } \\
\text { Pre-school, family-based programmes showed mixed effects on } \\
\text { alcohol use in later adult life } \\
\text { Manualised universal community-based multi-component } \\
\text { programme targeting alcohol misuse } \\
\text { Universal school-based tobacco prevention programmes } \\
\text { Community-based tobacco prevention programmes when } \\
\text { delivered in combination with a school-based programme } \\
\text { Mass media approaches to tobacco prevention, or the addition } \\
\text { of mass media components to community activities } \\
\text { Some social influence programmes can produce short-term } \\
\text { reductions in cannabis use, particularly in low-risk } \\
\text { populations } \\
\text { Parental programmes for parents designed to reduce use of } \\
\text { multiple substances by young people. Where effective, } \\
\text { programmes included active parental involvement, or aimed } \\
\text { to develop skills in social competence, self-regulation, and } \\
\text { parenting skills. }\end{array}$ \\
\hline
\end{tabular}




\begin{tabular}{|c|c|}
\hline $\begin{array}{l}\text { Unknown effectiveness } \\
\text { Interventions and approaches for } \\
\text { which there were not enough studies } \\
\text { to demonstrate positive effects on } \\
\text { addictive behaviours, or where } \\
\text { available studies were of low quality } \\
\text { (with few participants or with } \\
\text { uncertain methodological rigour), } \\
\text { making it difficult to assess if they } \\
\text { were effective or not. }\end{array}$ & $\begin{array}{l}\text { Universal family-based programmes for the prevention of } \\
\text { illegal drug use. }\end{array}$ \\
\hline $\begin{array}{l}\text { Ineffective } \\
\text { Interventions and approaches which } \\
\text { produced negative effects on addictive } \\
\text { behaviours when compared to a } \\
\text { standard intervention or no } \\
\text { intervention. For ethical reasons, it } \\
\text { must be considered whether such } \\
\text { interventions and approaches should } \\
\text { be discontinued as they may } \\
\text { sometimes have iatrogenic effects (i.e. } \\
\text { they increase a behaviour that is trying } \\
\text { to be prevented). }\end{array}$ & $\begin{array}{l}\text { Mailed, group feedback, and social-marketing-based } \\
\text { approaches to reduce alcohol misuse } \\
\text { Web and computer-based interventions to prevent tobacco } \\
\text { use } \\
\text { - Universal family-based programmes to prevent tobacco use } \\
\text { Use of competition incentives to prevent tobacco use in school } \\
\text { children } \\
\text { Ethnically tailored tobacco prevention is ineffective in } \\
\text { indigenous youth (NB evidence is from North American } \\
\text { communities, we do not have equivalent data for the UK) } \\
\text { Standalone school-based curricula designed only to increase } \\
\text { knowledge about illegal drugs } \\
\text { Recreational/diversionary activities, and theatre/drama } \\
\text { based education to prevent illegal drug use } \\
\text { Individual programmes that have combined school and } \\
\text { community-based interventions to prevent illegal drug use } \\
\text { Mentoring programmes have no short- or long-term } \\
\text { preventative effects on illegal drug use } \\
\text { Mass media programmes targeting illegal drug use. }\end{array}$ \\
\hline
\end{tabular}

Table 1 'What works' in substance use prevention for young people - a summary of Brotherhood et al., 2013. Approaches specifically addressing illegal drug use are in bold text. Please note that prevention approaches not included in this table had not been included in a systematic review, even though high-quality primary studies may exist.

In addition to potentially beneficial approaches to prevention, research has shown that a number of named prevention interventions are likely to be beneficial, and many are likely to be cost-effective. Such programmes are named in systematic reviews, databases of effective programmes, and have been subject to high-quality research. These are often referred to as manualised interventions and are characterised as having been standardised through the creation of manuals and protocols for those who implement it. Three manualised intervention examples of relevance to the UK (having been trialled, piloted, or currently being implemented; NB other programmes are available) include:

Preventure - a school-based intervention, trialled in the UK, that targets four personality risk-factors for earlyonset drinking or illicit drug use: hopelessness, anxiety-sensitivity, impulsivity and sensation-seeking. The programme uses psycho-educational manuals within interactive group sessions with students aged 13-16 years. The group sessions focus on motivational factors for risky behaviours and provide students with coping skills to aid their decision making in situations involving, anxiety and depression, thrill seeking, aggressive and risky behaviour (e.g. theft, vandalism and bullying), drugs and alcohol misuse. This intervention is associated with two-year reductions in problem-drinking symptoms and illicit drug use in high risk youth. ${ }^{65}{ }^{66}$ Secondary analyses have shown that the intervention also impacts on youth mental health outcomes, such as depression, anxiety, and conduct problems over a two-year period. ${ }^{67}$ 
Good Behavior Game - an extensively researched classroom management activity delivered in primary school. The Game is played several times a week and rewards children for displaying appropriate behaviours during lessons (e.g. not talking out of turn or leaving a seat without permission) and is thought to work by improving socialisation skills in the classroom. The class is divided into two teams and a point is given to a team for rule breaking by one of its members. The team with the fewest number of points at the Game's conclusion each day wins a group reward. If both teams keep their points below a threshold, then both teams share in the reward. In one long-term trial conducted in the USA, participation in the Game in primary school was associated at age 19-21 with significantly lower rates of drug and alcohol use disorders, regular smoking, antisocial personality disorder, delinquency and imprisonment for violent crimes, suicide ideation, and use of school-based services. ${ }^{68}$ This intervention is particularly notable not only because of its apparent longevity of effect but also because it is one of several interventions that have an impact on substance use without directly mentioning drugs. ${ }^{69}$

Strengthening Families - a family skills programme that, in different forms, is suitable for high-risk and universal populations. The programme consists of weekly sessions, lasting two to three hours. For the first hour, parallel groups of children and parents develop their understandings and skills led by two parent and two child trainers. In the second hour parents and children come together as individual family units to practise the principles they have learned. The remaining time is spent on family logistics, meals, and other family activities. There is good evidence that participation leads to improved family, parental and child functioning and of a reduction in substance use initiation and associated problems and a reduction in its severity (see summary by Kumpfer, $2004^{70}$ ).

It is also important to note that existing evidence in no way guarantees that positive prevention outcomes will be achieved, even when effective interventions are implemented. In most cases, more research is needed to determine whether the success of these interventions can be replicated in real-world settings in routine practice (i.e. outside of the idealised environment of the research trial), within current prevention structures and policy, and how programmes and policies can be effectively implemented and disseminated. Public acceptability of intervention also needs to be taken into account, particularly with regards to those measures that aim to restrict behaviours to achieve health outcomes. For example, research evidence shows that the general public are more likely to accept the least intrusive behaviour change interventions, which are often the least effective, and those interventions that target the behaviour of others, rather than the respondent themselves. ${ }^{71}$

Special consideration needs to be made of economic analysis of prevention activities (see Caulkins et al., $2014^{72}$ for an accessible overview of the field). While Benjamin Franklin's 'An ounce of prevention is worth a pound of cure' remains relevant and persuasive, this only remains true for activities that have been subject to appropriate investigation. A particular prevention programme or policy may be effective, but if it is economically inefficient then it does not represent good value for money, and expenditure targeted towards one group means that less resource will be available for another. Conducting economic evaluations in prevention is difficult, but a number of analyses have been published. For reference, the Washington State Institute has published cost-benefit assessments for several USA policies and programmes ${ }^{73}$ in order to aid decision making. For example, it is estimated that the Good Behavior Game costs $\$ 156$ per pupil to implement, but provides total benefits (in terms of costs avoided) of $\$ 13,206$, a clear positive benefit to cost ratio of \$84.63. In contrast, the Scared Straight adolescent justice programme costs $\$ 66$ per participant, and as it is associated with worse outcomes for participants and society, leads to additional outcome-related costs of $\$ 12,932$, a negative benefit-to-cost ratio of $\$ 195.93$. These two extreme ratios allow for relatively easy decision making on the basis of cost. However, decision making may be more difficult where savings ratios are marginal, or where an activity is cost saving, but requires large initial expenditure. Furthermore, economic (and often health and social) benefits of prevention are often only seen in the long term, which has both budgetary and political implications. 
There is a lack of UK economic data for prevention, so the limited research that has been undertaken has used economic modelling techniques, calculating how effective a programme would have to be in order to be costeffective for a given cost. Metrics and methodologies vary between organisations, but in the UK, NICE use costutility approaches such as 'cost per case avoided' (e.g. cost in $f$ per case of harmful drinking avoided at specified follow-up timepoints), or base decisions on 'willingness to pay thresholds' for a gain in Quality Adjusted Life Years (QALYS). QALYs are calculated by estimating the years of life remaining for an individual following a particular treatment or intervention, and weighting each year with a quality of life score (on a zero to 1 scale). This is often measured in terms of the person's ability to perform the activities of daily life, and freedom from health problems. NICE typically set a number of willingness to pay thresholds to aid decision making. Using such techniques, NICE have estimated that with respect to alcohol, a school-based prevention programme could be cost-effective if it cost $f 75$ million and achieved at least a $1.4 \%$ reduction in alcohol consumption among recipients ${ }^{74}$.

Where there is uncertainty about the effectiveness of a particular approach a precautionary pragmatism should apply (see Foxcroft, $2005^{75}$ ). Clearly ineffective approaches, or approaches where the targeted behaviour is not associated with harm, should not be commissioned. Uncertainty about the effectiveness of a prevention activity should not, however, preclude its use where delivery is part of a research activity and the balance of probability suggests the prevention activity is unlikely to be associated with harm. Such approaches are also justified if the costs and harms associated with a lack of action are considered to be high. It should also be recognised that prevention approaches may be useful, even if they do not directly lead to changes in outcomes such as drug use, if they support other activities which might be useful in other parts of the in the prevention 'system'. For example, an activity that increases trust and acceptance towards a prevention service, making future engagement and retention more likely, is a beneficial action. The logic of such approaches should, however, be justified and evidence presented on how they support prevention outcomes. 


\section{REFERENCES}

${ }^{1}$ ACMD (2006) Pathways to Problems. Hazardous use of tobacco, alcohol and other drugs by young people in the UK and its implications for policy. London: COI

${ }^{2}$ ACMD (2009) Pathways to Problems. A follow-up report on the implementation of recommendations from Pathways to Problems. London: Home Office

${ }^{3}$ NICE (2007) Interventions to reduce substance misuse among vulnerable young people. NICE Guidelines PH4 London: NICE

${ }^{4}$ HM Government (2010) Drug Strategy 2010 Reducing Demand, Restricting Supply, Building Recovery: Supporting people to live a drug free life. London: Home Office

${ }^{5}$ HM Government (2010) Drug Strategy 2010 Evaluation Framework - evaluating costs and benefits. London: Home Office.

${ }^{6}$ Faggiano F, Vigna-Taglianti F, Versino E, Zambon A, Borraccino A, Lemma P (2005) School-based prevention for illicit drugs' use. Cochrane Database of Systematic Reviews 2: CD003020. DOI: 10.1002/14651858.CD003020.pub2.

${ }^{7}$ Moreira MT, Smith LA, Foxcroft D (2009) Social norms interventions to reduce alcohol misuse in university or college students. Cochrane Database of Systematic Review :CD006748. doi:10.1002/14651858.CD006748.pub2.

${ }^{8}$ Sumnall HR, Bellis MA (2007) Can health campaigns make people ill? The iatrogenic potential of populationbased cannabis prevention. Journal of Epidemiology and Community Health 61:930-931

${ }^{9}$ Babor TF, Poznyak V (2010) The World Health Organization Substance Abuse Instrument for mapping services', Nordic Studies on Alcohol and Drugs 27(6): 703-12

10 Ritter A \& McDonald D (2008) 'Illicit drug policy: scoping the interventions and taxonomies'. Drugs: education, prevention and policy vol. 15, no. 1, pp. 15-35

${ }^{11}$ Shiell A, Hawe P, Gold L (2008) Complex interventions or complex systems? Implications for health economic evaluation. BMJ 336: 1281-1283

${ }^{12}$ Sussman S, Levy D, Hassmiller Lich K, W Cené CW, Kim MM, Rohrbach LA, Chaloupka FJ (2013) Comparing effects of tobacco use prevention modalities: need for complex system models. Tobacco Induced Diseases 11:2

${ }^{13}$ Grant A (2013) The economic cost of smoking to Wales: a review of existing evidence. Cardiff: ASHWales

${ }^{14}$ http://www.whitehouse.gov/ondcp/anti-drug-media-campaign

${ }^{15}$ Hornik R, Jacobsohn L, Orwin R, Piesse A and Kalton G (2008) Effects of the National Youth Anti-Drug Media Campaign on Youths. Am J Public Health. 2008 December; 98(12): 2229-2236

${ }^{16}$ Longshore D, Ghosh-Dastidara B, Ellicksona PL (2006) National Youth Anti-Drug Media Campaign and schoolbased drug prevention: Evidence for a synergistic effect in ALERT Plus. Addictive Behaviors Volume 31, Issue 3, March 2006, Pages 496-508

${ }^{17}$ Rehm J, Babor TF, Room R (2006) Education, persuasion and the reduction of alcohol-related harm: a reply to Craplet (2006). Addiction 101: 452-3

${ }^{18}$ E.g. http://tobaccofreefutures.org/

${ }^{19}$ Brotherhood A, Sumnall HR (2011) European drug prevention quality standards. Lisbon: EMCDDA

${ }^{20}$ Institute of Medicine (1994) Reducing Risks for Mental Disorders: Frontiers for Preventive Intervention Research. In: Mrazek PJ, Haggerty RJ, editors. Committee on Prevention of Mental Disorders, Division of Biobehavorial Sciences and Mental Disorders. Washington, DC: National Academy Press

${ }^{21}$ Foxcroft D (2013) Can Prevention Classification be Improved by Considering the Function of Prevention? Prevention Science DOI 10.1007/s11121-013-0435-1

${ }^{22}$ Sumnall HR, Brotherhood A (2012) Social reintegration and employment: evidence and interventions for drug users in treatment. EMCCDA Insights 13. Lisbon: EMCDDA 
${ }^{23}$ Hawkins JD, Catalano RF, Miller JY (1992) Risk and protective factors for alcohol and other drug problems in adolescence and early adulthood: implications for substance abuse prevention. Psychological Bulletin 112:64105

${ }^{24}$ Birckmayer JD, Holder HD, Yacoubian GS, Friend KB (2004) A general causal model to guide alcohol, tobacco, and illicit drug prevention: Assessing the research evidence. Journal of Drug Education 34: 121-153

${ }^{25}$ Blum RW, Bastos FIPM, Wabiru CW, Le LC (2012) Adolescent health in the $21^{\text {st }}$ century. The Lancet 379:15671568

${ }^{26}$ Patton GC, Coffey C, Cappa C, Currie D, Riley L, Gore F, Degenhardt L, Richardson D, Astone N, Sangowawa AO, Mokdad A, Ferguson J (2012) Health of the world's adolescents: a synthesis of internationally comparable data. The Lancet 379:1665-1675

${ }^{27}$ Viner RM, Ozer EM, Denny S, Marmot M, Resnick M, Fatusi A, Currie C (2012) Adolescence and the social determinants of health. The Lancet 379: 1641-1652

${ }^{28}$ Vanyukova MM, Tartera RE, Kirillovaa GP, Kiriscia L, Reynolds MD, Kreekd MJ, Conwaye KP, Maherf BS, laconog WG, Bieruth L, Nealei MC, Clark DB, Ridenoura T (2012) Common liability to addiction and "gateway hypothesis": Theoretical, empirical and evolutionary perspective. Drug and Alcohol Dependence. 123: S3-S17

${ }^{29}$ Hale DR, Viner RM (2012) Policy responses to multiple risk behaviours in adolescents. Journal of Public Health 34 (S1): 11-19

${ }^{30}$ Prochaska JJ, Spring B, Nigg CR (2008) Multiple health behavior change research: an introduction and overview. Prev Med 2008;46:181-8

${ }^{31}$ Werch CE, Moore MJ, Bian H, DiClemente CC, Huang I-C, Ames SC, Thombs D, Weiler RM, Pokorny SB (2010) Are effects from a brief multiple behavior intervention for college students sustained over time? Preventive Medicine, 50, 30-34

${ }^{32}$ Measham F, Shiner Mv (2009) the legacy of 'normalisation': the role of classical and contemporary criminological theory in understanding young people's drug use. Int J Drug Policy. 2009 Nov;20(6):502-8

${ }^{33}$ Spector M, Kitsuse JI (1987) Constructing Social Problems. Hawthorne, NY: Aldine de Gruyter

${ }^{34}$ Edman J (2013) An ambiguous monolith - the Swedish drug issue as a political battleground 1965-1981. International Journal of Drug Policy 24: 464-470

${ }^{35}$ Brown JH (2001) Youth, drugs and resilience education. Journal of Drug Education 31: 83-122

${ }^{36}$ Gorman DM (2005) Drug and violence prevention: Rediscovering the critical rational dimension of evaluation research. Journal of Experimental Criminology 1: 39-62

${ }^{37}$ Gandhi AG, Murphy-Graham E, Petrosino A, Chrismer SS, Weiss CH (2007) The devil is in the details: examining the evidence for "proven" school-based drug abuse prevention programs. Evaluation Review 31:4374

${ }^{38}$ Midford R (2008). Is this the path to effective prevention? Addiction 103: 1169-70

${ }^{39}$ EMCDDA (2009) Preventing later substance use disorders in at-risk children and adolescents. Lisbon: EMCDDA

${ }^{40}$ Strang J, Babor T, Caulkins J, Fischer B, Foxcroft D, Humphreys K (2012) Drug policy and the public good: evidence for effective interventions. The Lancet 7: 71-83

${ }^{41}$ Hall W, Degenhardt L (2009) Adverse health effects of non-medical cannabis use. The Lancet 374: 1383-1391

${ }^{42}$ Fernandez-Hermida, JR, Calafat A, Becoña E, Tsertsvadze A, Foxcroft DR (2012) Assessment of generalizability, applicability and predictability (GAP) for evaluating external validity in studies of universal family-based prevention of alcohol misuse in young people: systematic methodological review of randomized controlled trials. Addiction 107: 1570-1579

${ }^{43}$ Small individual gains may become important when considered at a population level, e.g. the effects of alcohol minimum unit pricing on population health. 
${ }^{44}$ Botvin G, Mihalic S, Grotpeter JK (1998) (Eds.). Life Skills Training. Vol. 5. Boulder, CO: Center for the Study and Prevention of Violence, Institute of Behavioral Science, University of Colorado

${ }^{45}$ Spoth R, Shin C, Guyll M, Redmond C, Azevedo K (2006) Universality of effects: An examination of the comparability of long-term family intervention effects on substance use across risk-related subgroups. Prevention Science 7: 209-224

${ }^{46}$ Gardner F, Connell A, Trentacosta CJ, Shaw DS, Dishion TJ, Wilson MN (2009) Moderators of outcome in a brief family-centered intervention for preventing early problem behavior. Journal of Consulting and Clinical Psychology: 77, 543-553

${ }^{47}$ Spoth R, Redmond C, Shin C, Greenberg M, Clair S, Feinberg M (2007) Substance use outcomes at 18 months past baseline: The PROSPER community-university partnership trial. American Journal of Preventive Medicine. 32: 395-402

${ }^{48}$ Tolan P, Gorman-Smith D, Henry D (2004) Supporting families in a high-risk setting: Proximal effects of the SAFE Children preventive intervention. Journal of Consulting and Clinical Psychology 72: 855-869

${ }^{49}$ Bierman KL, Coie JD, Dodge KA, Foster EM, Greenberg MT, Lochman JE, McMahon RJ, Pinderhughes EE (2007) Fast track randomized controlled trial to prevent externalizing psychiatric disorders: Findings from grades 3 to 9. Journal of the American Academy of Child and Adolescent Psychiatry 46: 1250-1262

${ }^{50}$ Kellam SG, Brown CH, Poduska JM, lalongo NS, Wang W, Toyinbo P, Petras H, Ford C, Windham A, Wilcox HC (2008). Effects of a universal classroom behavior management program in first and second grades on young adult behavioral, psychiatric, and social outcomes. Drug and Alcohol Dependence 95: S5-S28

${ }^{51}$ Eisen M, Zellman GL, Massett HA, Murray DM (2002) Evaluating the Lions-Quest "Skills for Adolescence" drug education program: First-year behavior outcomes. Addictive Behaviors 27: 619-632

${ }^{52}$ Perry CL, Williams CL, Komro KA, Veblen-Mortenson S, Stigler MH, Munson KA, Farbakhsh J, Jones RM, Forster JL (2002) Project Northland: Long-term outcomes of community action to reduce adolescent alcohol use. Health Education Research 17: 117-132

${ }^{53}$ Spoth R, Shin C, Guyll M, Redmond C, Azevedo K (2006) Universality of effects: an examination of the comparability of long-term family intervention effects on substance use across risk-related subgroups. Prevention Science. 7:209-24

${ }^{54}$ Catalano RF, Fagan AA, Gavin LE, Greenberg MT, Irwin CE, Ross DA, Shek DTL (2012) Worldwide application of prevention science in adolescent health. The Lancet 379: 1653-1664

${ }^{55}$ Salz R, Biglan A, Brotman L, Castro F, Gorman-Smith D (2012) Advocacy for prevention Science. Fairfax, Virginia, Society for Prevention Research

${ }^{56}$ Brotherhood A, Sumnall HR (2011) European drug prevention quality standards. Lisbon: EMCDDA

${ }^{57}$ Flay BR, Biglan A, Boruch RF, Castro FG, Gottfredson D, Kellam S, Mościcki EK, Schinke S, Valentine JC, Ji P (2005) Standards of evidence: criteria for efficacy, effectiveness and dissemination. Prevention Science 6:151175

${ }^{58}$ Werch CE, Owen DM (2002) latrogenic effects of alcohol and drug prevention programs. Journal of Studies on Alcohol 63: 581-590

${ }^{59}$ Bonell C, Fletcher A, Morton M, Lorenc T, Moore L (2012) Realist randomised controlled trials: a new approach to evaluating complex public health interventions. Social Science and Medicine 75: 2299-2306

${ }^{60}$ https://www.unodc.org/unodc/en/prevention/prevention-standards.html

${ }^{61}$ http://www.ifs.org.uk/centres/caytRepPublications

62 http://www.nrepp.samhsa.gov/

63 http://www.thecochranelibrary.com/view/0/index.html

${ }^{64}$ Brotherhood AB, Atkinson A, Bates G, Sumnall HR (2013) Adolescents as customers of addiction. ALICE RAP Deliverable 16.1, Work Package 16. Background report 2: Review of reviews. Liverpool: Centre for Public Health 
${ }^{65}$ Conrod PJ, Castellanos-Ryan N, Strang J (2010) Brief, personality-targeted coping skills interventions and survival as a non-drug user over a 2-year period during adolescence. Archives of General Psychiatry 67: 85-93.

${ }^{66}$ Conrod PJ, Castellanos-Ryan N, Mackie C (2011) Long-term effects of personality-targeted interventions to reduce alcohol use in adolescents. Journal of Consulting and Clinical Psychology 79: 296-306

${ }^{67}$ O'Leary-Barrett M, Mackie CJ, Castellanos-Ryan, N, Al-Khudhairy N, Conrod PJ (2010) Personality-targeted interventions delay uptake of drinking and decrease risk of alcohol-related problems when delivered by teachers. Journal of the American Academy of Child and Adolescent Psychiatry 49: 954-963

${ }^{68}$ Kellam SG, Mackenzie ACL, Brown CH, Poduska JM, Wang W, Petras H,. Wilcox HC (2011) The Good Behavior Game and the Future of Prevention and Treatment. Addict Sci Clin Pract. 6(1): 73-84

${ }^{69}$ Ashton M (2013) It's magic: prevent substance use problems without mentioning drugs http://findings.org.uk/count/downloads/download.php?file=hot no drugs.hot (last accessed 13/5/14)

${ }^{70}$ Kumpfer K (2004) Doing it together strengthens families and helps prevent substance use. Drug and Alcohol Findings 10

${ }^{71}$ Diepeveen S, Ling T, Suhrcke M, Roland M, Marteau TM (2013) Public acceptability of government intervention to change health-related behaviours: a systematic review and narrative synthesis. BMC Public Health 2013, 13:756

${ }^{72}$ Caulkins J, Nicosia N, Pacula RL (2014) Economic Analysis and Policy Studies: Special Challenges in the Prevention Sciences. In (Eds. Slobod Z, Petras H) Defining Prevention Science. Springer

${ }^{73}$ http://www.wsipp.wa.gov/BenefitCost

${ }^{74}$ Nherera L, Jacklin P (2009) A model to assess the cost-effectiveness of alcohol education developed for NICE public health guidance on personal, social, health and economic (PSHE) education. London: NICE

${ }^{75}$ Foxcroft DF (2005) The need for values. Science and art in alcohol harm reduction. Addiction 102: 1350-1351 